\title{
Medication-related osteonecrosis of the jaws (MRONJ) and the time to event: $A$ retrospective study
}

\author{
Cameron YS Lee (DMD, MD, PHD) ${ }^{1 *}$, Cameron CY Lee (BS) ${ }^{2}$ and Jon B Suzuki (DDS, PHD, MBA) ${ }^{3}$ \\ ${ }^{1}$ Clinical Professor, Department of Periodontology and Oral Implantology, Kornberg School of Dentistry, Temple University, Philadelphia, PA, USA; Private \\ practice in Aiea, Hawaii \\ ${ }^{2}$ Dental Student, Harvard School of Dental Medicine, Boston, MA, USA \\ ${ }^{3}$ Professor and Chair, Department of Periodontology and Oral Implantology, Kornberg School of Dentistry, Temple University, Philadelphia, PA, USA
}

\begin{abstract}
Purpose: Osteonecrosis of the jaw (ONJ) is a rare disease of patients prescribed oral antiresorptive (AR) medications. The goal of this study is to evaluate the time to ONJ after dentoalveolar surgery, the duration of antiresorptive therapy and the incidence of developing ONJ.

Materials and Methods: We conducted a retrospective cohort study of 388 patients from a private oral and maxillofacial surgery practice to evaluate the time to ONJ, the oral drug duration and incidence after surgery involving the jaws.

Results: A total of 388 patients who underwent 551 surgical procedures of the maxilla and mandible were evaluated from January 2006 to March 2013. Seven patients $(1.8 \%)$ were observed to develop ONJ after dentoalveolar surgery. Patients developing ONJ reported 1.73 times greater duration of drug therapy compared to controls $(\mathrm{p}=0.0002)$. In particular, patients prescribed Fosamax who developed ONJ had 1.69 times greater cumulative doses than that of the controls ( $\mathrm{p}=0.0014)$. The mean time to event for ONJ was approximately 55.8 months with a minimum onset of 20 months. Patients presenting with ONJ as a complication of tooth extraction presented 48.8 months earlier than patients presenting with ONJ as a complication of dental implant surgery $(\mathrm{p}=0.0194)$.

Conclusions: The mean time to ONJ after extraction of teeth occurs much sooner compared to ONJ after dental implant surgery. With the extremely low cumulative incidence of $\mathrm{ONJ}$ in patients prescribed antiresorptive medications, dentoalveolar surgery should not be avoided in this group of patients, as ONJ is a rare complication of antiresorptive drug therapy.
\end{abstract}

\section{Introduction}

Medication-related osteonecrosis of the jaw (MRONJ) is a rare disease characterized by exposed bone with or without pain of patients prescribed oral antiresorptive medication in the treatment of osteoporosis or osteopenia to prevent skeletal related events (SRE), such as hip and vertebral fractures, spinal cord compression and hypercalcemia of malignancy [1-5]. It is estimated that $47 \%$ of women and $22 \%$ of men 50 years of age and older will experience an osteoporotic fracture during their lifetime [6,7]. Both conditions increase the risk of skeletal fracture, most commonly the arm, hip, pelvis and vertebral bodies. The clinical significance is the risk of skeletal fractures, with increased disability, morbidity and mortality [8]. Annually, there are greater than 1.5 million skeletal fractures in the United States [9]. Therefore, the prevention and management of osteoporosis is of extreme importance.

Oral antiresorptive agents are considered the standard of care for the prevention and treatment of women with postmenopausal osteoporosis and are the most widely used medications for this skeletal disorder [10-13]. Orally administered antiresorptive agents approved by the United States Food and Drug Administration (FDA) include the following: Alendronate sodium (Fosamax; Merck \& Co., Inc.; Whitehouse Stations, NJ); Risedronate sodium (Actonel, Warner Chilcot, Dublin) and Ibandronate sodium (Boniva, Roche Group, South San Francisco). Each of the medications differ in their binding affinity to bone, potency and duration $[14,15]$.
Osteonecrosis of the jaws (ONJ) is a complication that occurs after a surgical procedure that directly involves the jaw bones, such as tooth extraction, bone grafting of the jaws in preparation for dental implants, and implant surgery [16-18]. It is associated with current or former antiresorptive (AR) drug therapy and that $\mathrm{ONJ}$ is both a time-dependent and dose dependent disease process $[19,20]$. There is a paucity of data regarding the correlation of dental implant treatment with the development of medication-related osteonecrosis of the jaws (MRONJ). The etiology of ONJ due to antiresorptive therapy remains unknown, but several hypotheses have been formulated to discuss the possible mechanism responsible for this pathologic condition [16,2130]. All of the above theories attempt to explain the pathogenesis of MRONJ. However, they fail to explain why nitrogen containing bisphosphonates result in osteonecrosis of the jaws, but not other parts of the skeletal bones.

At present, there are no published studies that have accurately determined the onset of ONJ and the true incidence of developing MRONJ. This is due to the fact that most reports are retrospective

Correspondence to: Cameron Y.S. Lee, 98-1247 Kaahumanu Street, Suite 314, Aiea, Hawaii 96701, USA, Tel: 808-484-2288; FAX: 808-484-1181; E-mail: CLee555294@aol.com

Received: August 20, 2015; Accepted: October 02, 2015; Published: October 05,2015 
studies and case reports. Most cases of ONJ are associated with long term therapy with antiresorptive agents and administration of the intravenous agents Zoledronic acid (Zometa; Novartis Pharmaceuticals Co; East Hanover, NJ) and Pamidronate (Aredia; Novartis Pharmaceuticals Co; East Hanover, NJ) [31,32]. The incidence of MRONJ for patients taking the intravenous form of this medication is estimated at $2 \%$ to $18 \%[33,34]$. The American Association of Oral and Maxillofacial Surgeons position paper on antiresorptive agent related ONJ estimate the incidence of ONJ cases for patients taking the oral form as 0.01 to $0.04 \%$ [32]. Suggested risk factors that may contribute to $\mathrm{ONJ}$ besides oral antiresorptive drug therapy include advanced age, and systemic and local risk factors. The number of reported cases of ONJ from oral antiresorptive therapy has slowly increased since 2003 and will continue to increase over the next several years as the general population continues to age. There is a lack of data in the dental literature that describes the time to $\mathrm{ONJ}$ and antiresorptive drug duration in the dentoalveolar surgery patient.

The purpose of the present study was to assess the incidence and course of onset of ONJ in the private practice setting. Data was obtained to determine the mean and minimum time to event of ONJ after dentoalveolar surgery involving the jaw bones and the mean and minimum cumulative dose at the time of ONJ. We also calculate the incidence of MRONJ in this patient cohort.

\section{Patients and methods}

This was a retrospective study that utilized a cohort of adult patients from January 2006 to March 2013 presenting to the office of one of the authors (CYSL) for oral and maxillofacial surgery. Each patient was asked to provide a complete medical history. Inclusion criteria for patient participation in this study were medical treatment for osteoporosis or osteopenia with any of the nitrogen containing oral antiresorptive medications. Demographic data, such as ethnicity, medical co-morbidities, metabolic bone diseases such as osteopenia and osteoporosis, and current medications were obtained. Time to event (mean and minimum) and antiresorptive medication dose were calculated to determine when signs and symptoms may first appear in patients prescribed oral antiresorptive medications after completing any type of surgery involving the jaw bones. An event was defined as a patient presenting with signs and symptoms of MRONJ following any surgical procedure involving the jaw bones.

We utilized the classification of the American Association of Oral and Maxillofacial Surgeons (AAOMS) [35,36] to define the stage of ARONJ that consist of four stages (0-3). The diagnosis of MRONJ is based on the following characteristics: A history of antiresorptive therapy; exposed jaw bone for 8 weeks or greater; no history of radiation therapy where the jaw bones were in the field of radiation. This clinical staging system has been established to define the severity of MRONJ and guide the clinician in the management of this surgical problem. Individuals previously prescribed the intravenous form of antiresorptive medications and individuals who received radiation to the oral and maxillofacial region for malignancies were excluded from this study (Table 1).

A total of 388 patients were recruited for inclusion in this study. Twenty two males and 366 females, ranging in age from 48 to 98 years (mean 74.4 years) underwent a total of 551 surgical procedures. There were 448 extractions, 65 dental implants surgically placed, and 6 sinus lift elevation procedures with bone graft augmentation. In each of the sinus graft surgeries, platelet rich plasma (PRP) was included to enhance soft and hard tissue healing. In addition, there were 23 bone grafts ( 5 particulate bone grafts and 18 block bone grafts) completed in the maxilla and mandible and six tori removed from the jaws. Of the 388 patients, 29 patients presented to the office for surgery on different dates for additional surgical procedures. Each surgical encounter was documented as a first-time patient and surgical procedure.

\section{Antiresorptive therapy duration}

Antiresorptive therapy duration was calculated using the patient's self reporting with the surgical record. The mean cumulative dose of oral antiresorptive therapy was documented from the year of initial physician prescription to the first office visit for oral and maxillofacial surgery. Patients prescribed oral alendronate took $70 \mathrm{mg}$ weekly, while those taking oral risedronate took $35 \mathrm{mg}$ weekly. However, patients prescribed oral medications are often not completely compliant, and will miss doses of their medication. It is estimated that the compliance rate is only about $75 \%$ [37].

\section{Statistical analysis}

Statistical analysis was performed using Graphpad Prism 5.0 (Graphpad, La Jolla, CA). Data are presented as mean \pm standard deviation. Descriptive and bivariate statistics were computed to compare cases and controls. Comparisons were performed using the Student's t-test. For all analyses a p-value of less than 0.05 was considered statistically significant.

\section{Results}

General demographic information is presented in Tables 2 and 3. Briefly, there were 388 participants (366 female and 22 male) with a mean age of $74.5 \pm 9.94$ years. The mean cumulative duration of pharmacologic therapy was $6.26 \pm 3.16$ years. The mean duration for all participants taking Fosamax was $80.75 \pm 38.2$ months compared to $59.80 \pm 31.2$ months for Actonel. There were 381 control patients and 7 cases of MRONJ in the study sample.

The case group consisted of 7 Asian females that we identified who

Table 1. MRONJ staging and treatment strategies - Staging and treatment strategy of MRONJ according to the position paper of the 2014 American Association of Oral and Maxillofacial Surgeons (AAOMS).

\begin{tabular}{|l|l|l|}
\hline Stage & Description & Treatment \\
\hline 0 & $\begin{array}{l}\text { Non-specific clinical findings, radiographic findings and symptoms. No clinical } \\
\text { evidence of necrotic bone. }\end{array}$ & Systemic management. Use of analgesics and antibiotics \\
\hline 1 & $\begin{array}{l}\text { Asymptomatic, but exposed and necrotic bone or fistulas are present. No evidence } \\
\text { of infection. }\end{array}$ & $\begin{array}{l}\text { Use of chlorhexidine mouthrinse, close monitoring of patient on quarterly basis. } \\
\text { Provide patient education. }\end{array}$ \\
\hline 2 & $\begin{array}{l}\text { Exposed necrotic bone or fistulas that probes to bone in area of infection. Clinical } \\
\text { signs of infection, such as pain, erythema with or without purulent discharge. }\end{array}$ & $\begin{array}{l}\text { Symptomatic treatment with antibiotics, oral bacterial mouthrinse, pain control, } \\
\text { debridement of infected area }\end{array}$ \\
\hline 3 & $\begin{array}{l}\text { Exposed necrotic bone or fistulas present that probes to bone and extends beyond } \\
\text { region of alveolar bone, such as to inferior border of mandible, ramus of mandible, } \\
\text { and zygoma in maxilla. Fracture of jaw or osteolysis present in jaws. }\end{array}$ & $\begin{array}{l}\text { All of the above treatment, plus more aggressive surgical intervention, such as } \\
\text { debridement and resection of jaw. }\end{array}$ \\
\hline
\end{tabular}


Table 2. Summary of Study Variables. Data are presented as $\mathrm{n} \pm$ standard deviation.

\begin{tabular}{|l|c|c|c|}
\hline Variable & Case & Control & Study Sample \\
\hline Age (Continuous) & $79.4 \pm 7.18$ years & $74.5 \pm 9.94$ years & $74.5 \pm 9.94$ years \\
\hline Sex (Binary) & & & \\
\hline Male & 0 & 22 & 22 \\
\hline Female & 7 & 359 & 366 \\
\hline $\begin{array}{c}\text { Duration of therapy } \\
\text { (Continuous) }\end{array}$ & $10.6 \pm 2.30$ years & $6.14 \pm 3.13$ years & $6.26 \pm 3.16$ years \\
\hline Fosamax & $11.3 \pm 0.88$ years & $6.73 \pm 3.18$ years & $6.81 \pm 3.21$ years \\
\hline Actonel & $8.85 \pm 4.45$ years & $4.98 \pm 2.60$ years & $5.05 \pm 2.66$ years \\
\hline $\begin{array}{c}\text { Cumulative dose } \\
\text { (Continuous) }\end{array}$ & $34086 \pm 12985 \mathrm{mg}$ & $19437 \pm 12232 \mathrm{mg}$ & $19913 \pm 12378 \mathrm{mg}$ \\
\hline Fosamax & $41277 \pm 3200 \mathrm{mg}$ & $24425 \pm 11564 \mathrm{mg}$ & $24738 \pm 11687 \mathrm{mg}$ \\
\hline Actonel & $16106 \pm 8107 \mathrm{mg}$ & $9069 \pm 4737 \mathrm{mg}$ & $9186 \pm 4840 \mathrm{mg}$ \\
\hline
\end{tabular}

Table 3. Summary of ARONJ Patients.

\begin{tabular}{|c|c|c|c|c|c|c|c|}
\hline $\begin{array}{c}\text { Patient } \\
\text { No. }\end{array}$ & Sex & Age & Medication & $\begin{array}{c}\text { Duration } \\
\text { (years) }\end{array}$ & $\begin{array}{c}\text { Cumulative } \\
\text { Dose (mg) }\end{array}$ & Procedure & $\begin{array}{c}\text { Time to Event } \\
\text { (months) }\end{array}$ \\
\hline 1 & F & 88 & Fosamax & 12.1 & 44044 & Implant & 83 \\
\hline 2 & F & 87 & Fosamax & 11.9 & 43316 & Extraction & 21 \\
\hline 3 & F & 85 & Actonel & 12 & 21840 & Implant & 84 \\
\hline 4 & F & 78 & Fosamax & 10 & 36400 & Implant & 95 \\
\hline 5 & F & 75 & Actonel & 5.7 & 10374 & Extraction & 43 \\
\hline 6 & F & 72 & Fosamax & 11.8 & 42952 & Extraction & 20 \\
\hline 7 & F & 71 & Fosamax & 10.9 & 39676 & Implant & 45 \\
\hline
\end{tabular}

exhibited signs and symptoms of MRONJ after surgery (Table 3). Of the seven cases, 3 occurred in the maxilla and 4 in the mandible. All patients exhibited stage 2 disease and had biopsy proven osteonecrosis of the jaws with actinomyces present. Three patients developed MRONJ in the posterior mandible following extraction of teeth that included exposure of bone, pain, and a non-healing extraction site beyond 8 weeks post-surgery. Four patients developed periimplantitis and eventually lost their implants, with 3 cases occurring in the posterior maxilla and one in the posterior mandible. The mean age of the patients with an MRONJ diagnosis was $79.4 \pm 7.18$ years, though there was no significant difference in age between cases and controls $(p=0.1891)$.

Patients with MRONJ reported 1.73 times greater duration of therapy compared to controls $(p=0.0002)$, (Figure 1$)$. The mean duration of therapy for patients with MRONJ taking Fosamax was $136.1 \pm 10.6$ months compared to $63.5 \pm 29.0$ months for Actonel. Within the subset of patients taking Fosamax, patients who developed MRONJ had 1.69 times greater duration of therapy than controls ( $p$ $=0.0014)$. However, there was no significant difference in duration of therapy between cases and controls in patients taking Actonel ( $p=$ 0.8682).

The incidence of developing MRONJ in this study was $1.8 \%$ (7/388) with a minimum and mean time to event of 20 months and 55.8 months, respectively. Patients who developed MRONJ after tooth extraction presented 48.75 months earlier than patients who developed MRONJ in association with periimplantitis $(p=0.0194)$ (Figures 2 and 3 ).

\section{Discussion}

In pharmacology and toxicology, the toxic lowest dose is defined as the medication administered (excluding inhalation) over a time period in humans or animals that will produce an observed toxicity, carcinogenic, teratogenic or neoplastic effect [38]. With antiresorptive medications used to treat osteoporosis, there are no published human clinical data describing the toxic lowest dose that will lead to osteonecrosis of the jaws. In their Fosamax clinical trials that involved over 17,000 patients, Merck reported no cases on ONJ [39].

In our seven patients, the mean time to MRONJ was 55.8 months with a minimum time to MRONJ was 20 months. However, the mean time to MRONJ based on surgical procedure reveals some interesting observations. After extraction of teeth, the mean time to MRONJ was 28 months compared to 76.7 months for patients exhibiting clinical signs of periimplantitis and eventual removal of the implant. The results of our study also indicate the MRONJ associated with dental implant loss is a late complication. Therefore, patients on antiresorptive medications

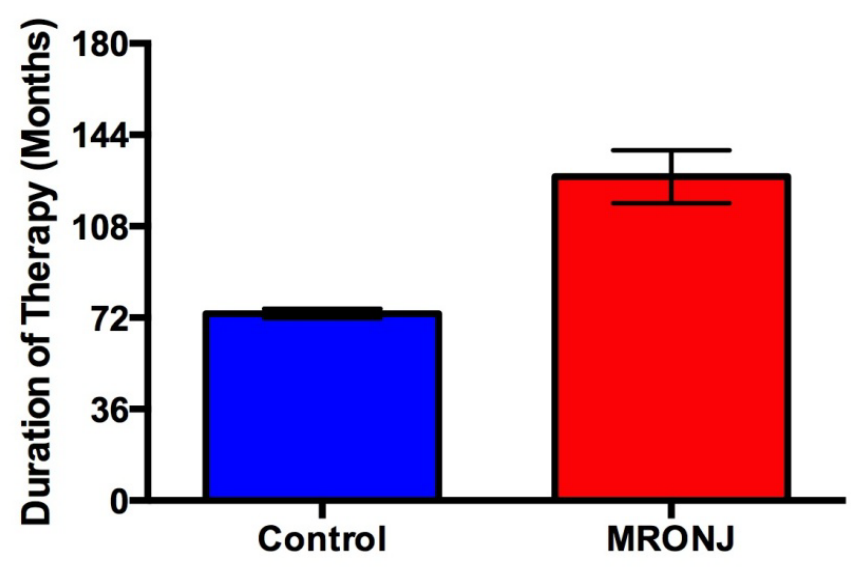

Cohort

Figure 1. Duration of therapy between cases and controls. Duration of bisphosphonate therapy was patient reported. Cases exhibited 1.73 times greater mean cumulative doses than controls $(p=0.0002)$. Patients prescribed Fosamax and Actonel are represented in this figure. Error bars represent 1 standard error.

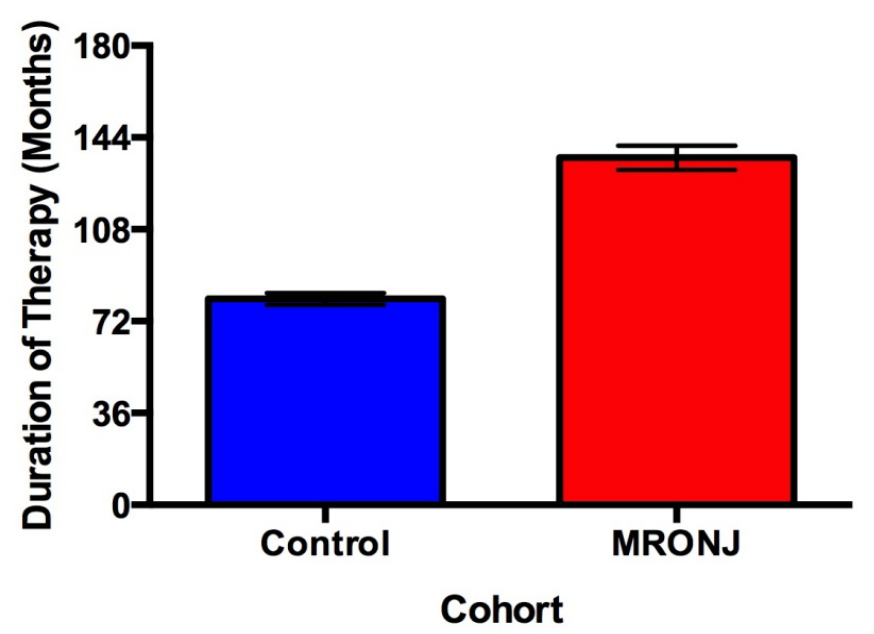

Figure 2. Duration of Fosamax therapy between cases and controls. Duration of bisphosphonate therapy was patient reported. Cases exhibited 1.69 times greater mean cumulative doses than controls $(p=0.0014)$. Error bars represent 1 standard error. 


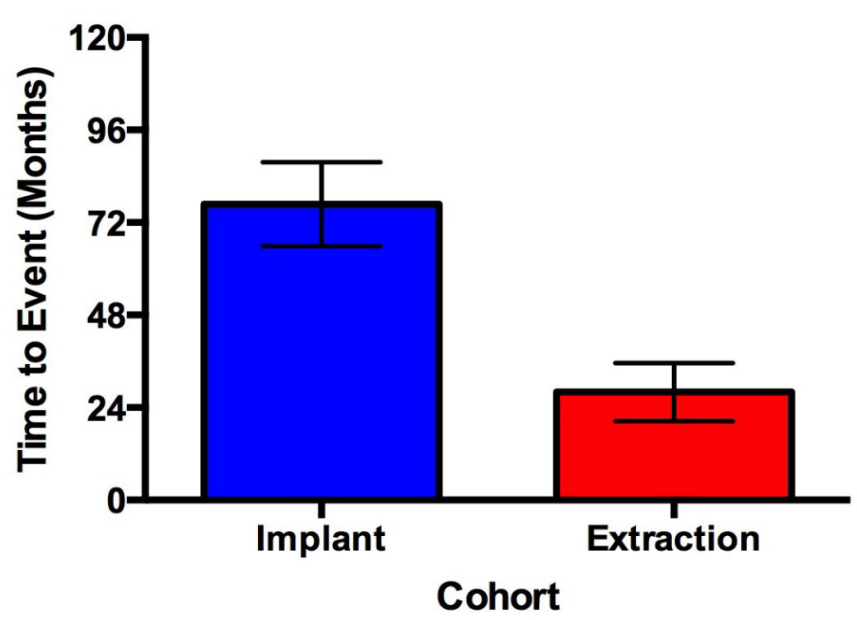

Figure 3. Time to event with regard to surgical procedure. Patients presenting with MRONJ underwent either tooth extraction or implant placement in a prior visit. Patients who developed MRONJ after tooth extraction presented 48.75 months earlier than patients who developed MRONJ in association with periimplantitis $(p=0.0194)$. Error bars represent 1 standard error.

and are treatment planned for dental implants should be informed of this potential late complication of implant loss and be followed for an indefinite period.

Several studies in the published literature regarding the mean time to event of MRONJ with oral antiresorptive therapy vary. Grana et al. [40] and Mavrokokki et al. [37] reported a mean time to event of MRONJ as early as 24 months, while Marx et al. [43] initial study reported a mean duration of 43 months. Nase and Suzuki [41] reported a mean time to MRONJ of 56 months, while Lazarovici and his colleagues [42] reported a mean time to event as just over 60 months after initiation of AR therapy. In the Kaiser Permanente PROBE study, [43] which is a mail survey that involved approximately 14,000 individuals, Lo et al. reported 9 patients diagnosed with ONJ associated oral antiresorptive therapy. Four of the cases occurred after dental extraction and the mean duration of antiresorptive drug therapy was 42 months (3.5 years).

There continues to be controversy if it is safe to surgically place dental implants in the patient prescribed antiresorptive medications. Case reports of early and late implant failures have been reported in the literature [44- 47]. According to the current AAOMS guidelines, [31,32] dental implant treatment is not a contraindication for the patient on antiresorptive therapy for osteoporosis. However, the potential for developing ARONJ after implant surgery remains unknown. There is a paucity of clinical cases in the literature describing a delay in wound healing, ONJ and implant loss in the patient prescribed oral antiresorptive medications compared to the implant patient not prescribed such medications [48-51]. These studies all concluded that there is no greater risk for the development of ONJ with oral antiresorptive therapy for the implant patient. In our four patients who developed periimplantitis and eventually lost their implants, three of the four implants were surgically placed in the posterior maxilla, while the last implant was in the posterior mandible. All lost implants were considered late (greater than 1 year after implant placement) failures.

Co-morbities, such as advanced age, diabetes mellitus, steroid therapy, history of malignancy and use of tobacco products were suggested as conditions that may increase the chances of developing MRONJ. In the present study, all seven patients were of advanced age, two patients had a history of diabetes mellitus, and two with a history of breast cancer. None of the seven patients had a history of using tobacco products. Based on the current literature, such co-morbidities may increase the risk of MRONJ and future implant loss.

To our knowledge, this is the first study to estimate the time to $\mathrm{ONJ}$ from use of antiresorptive medication after dentoalveolar surgery involving the jaw bones in a single private practice office. Conversely, most studies reported in the literature involve patients in a university teaching environment.

As dental implant treatment to replace missing teeth is the standard of care and with an aging population on oral antiresorptive therapy for osteoporosis, $\mathrm{ONJ}$ will continue to be an important issue for the patient who is considered an implant candidate. However, the extremely low incidence of developing $\mathrm{ONJ}$ in the patient prescribed these medications should not be a deterrent to any type of dentoalveolar surgery.

\section{References}

1. Papapoulos SE, Cremers SC (2007) Prolonged bisphosphonate release after treatment in children. N Engl J Med 356: 1075-1076. [Crossref]

2. Van den Wyngaert T, Claeys T, Huizing MT, Vermorken JB, Fossion E (2009) Initial experience with conservative treatment in cancer patients with osteonecrosis of the jaw (ONJ) and predictors of outcome. Ann Oncol 20: 331-336. [Crossref]

3. Lee CYS, Suzuki JB (2010) CTX biochemical marker of bone metabolism: is it a reliable predictor of bisphosphonate-associated osteonecrosis of the jaws after surgery? Part II: a prospective clinical study. Implant Dent 19: 29-38. [Crossref]

4. Nicolatou-Galitis O, Papadopoulous E, Sarri T, et al. (2011) Osteonecrosis of the jaw in oncology patients treated with bisphosphonates: prospective experience of a dental oncology referral center. Oral Surg Oral Med Oral Pathol Oral Radiol Endod 112:195202. [Crossref]

5. Wilde F, Heufelder M, Winter K, Hendricks J, Frerich B, et al. (2011) The role of surgical therapy in the management of intravenous bisphosphonates-related osteonecrosis of the jaw. Oral Surg Oral Med Oral Pathol Oral Radiol Endod 111: 153-163. [Crossref]

6. Larsen ER, Mosekilde L, Foldspang A (2004) Vitamin d and calcium supplementation prevents osteoporotic fractures in elderly community dwelling residents: a pragmatic population based 3-year intervention study. J Bone Miner Res 19: 370-378. [Crossref]

7. Boonen S, Bischoff-Ferrari HA, Cooper C, Lips P, Ljunggren O, et al. (2006) Addressing the musculoskeletal components of fracture risk with calcium and vitamin D: a review of the evidence. Calcif Tissue Int 78: 257-270. [Crossref]

8. Cummings SR, Melton LJ (2002) Epidemiology and outcomes of osteoporotic fractures. Lancet 359: 1761-1767. [Crossref]

9. Gabriel SE, Tosteson AN, Leibson CL, Crowson CS, Pond GR, et al. (2002) Direct medical costs attributable to osteoporotic fractures. Osteoporos Int 13: 323-330. [Crossref]

10. Rosen CJ (2005) Clinical practice. Postmenopausal osteoporosis. N Engl J Med 353 595-603. [Crossref]

11. Black DM, Delmas PD, Eastell R, Reid IR, Boonen S, et al. (2007) Once-yearly zoledronic acid for treatment of postmenopausal osteoporosis. $N$ Engl J Med 356: 1809-1822. [Crossref]

12. Khosla S (2009) Increasing options for the treatment of osteoporosis. $N$ Engl J Med 361: 818-820. [Crossref]

13. Favus MJ (2010) Bisphosphonates for osteoporosis. N Engl J Med 363: 2027-2035. [Crossref]

14. Genant HK, Cooper C, Poor G, Reid I, Ehrlich G, et al. (1999) Interim report and recommendations of the World Health Organization Task-Force for Osteoporosis. Osteoporos Int 10: 259-264. [Crossref]

15. Jamal SA, Leiter RE, Bayoumi AM, Bauer DC, Cummings SR (2005) Clinical utility of laboratory testing in women with osteoporosis. Osteoporos Int 16: 534-540. [Crossref]

16. Marx RE (2003) Pamidronate (Aredia) and zoledronate (Zometa) induced avascular necrosis of the jaws: A growing epidemic. J Oral Maxillofac Surg 61:1115-1117. [Crossref] 
17. Ruggiero SL, Mehrotra B, Rosenberg TJ, Engroff SL (2004) Osteonecrosis of the jaws associated with the use of bisphosphonates: a review of 63 cases. J Oral Maxillofac Surg 62: 527-534. [Crossref]

18. Marx RE, Sawatari Y, Fortin M, Broumand V (2005) Bisphosphonate-induced exposed bone (osteonecrosis/osteopetrosis) of the jaws: risk factors, recognition, prevention, and treatment. J Oral Maxillofac Surg 63: 1567-1575. [Crossref]

19. Migliorati CA, Siegel MA, Elting LS (2006) Bisphosphonate-associated osteonecrosis: a long-term complication of bisphosphonate treatment. Lancet Oncol 7: 508-514. [Crossref]

20. Marx RE, Cillo JE Jr, Ulloa JJ (2007) Oral bisphosphonate-induced osteonecrosis: risk factors, prediction of risk using serum CTX testing, prevention, and treatment. J Oral Maxillofac Surg 65: 2397-2410. [Crossref]

21. Migliorati CA, Casiglia J, Epstein J, Jacobsen PL, Siegel MA, et al. (2005) Managing the care of patients with bisphosphonate-associated osteonecrosis: an American Academy of Oral Medicine position paper. J Am Dent Assoc 136: 1658-1668. [Crossref]

22. Allegra A, Oteri G, Nastro E, et al. (2007) Patients with bisphosphonates-associated osteonecrosis of the jaw have reduced circulating endothelial cells in vitro. Hematol Oncol 25:164-169.

23. Landesberg R, Cozin M, Cremers S, Woo V, Kousteni S, et al. (2008) Inhibition of ora mucosal cell wound healing by bisphosphonates. J Oral Maxillofac Surg 66: 839-847. [Crossref]

24. Kyrgidis A, Triaridis S, Antoniades K (2009) Effects of bisphosphonates on keratinocytes and fibroblasts may have a role in the development of osteonecrosis of the jaw. Biosci Hypotheses 2:153.

25. Agis H, Blei J, Watzek G, Gruber R (2010) Is zoledronate toxic to human periodontal fibroblasts? J Dent Res 89: 40-45. [Crossref]

26. Otto S, Hafner S, Mast G, Tischer T, Volkmer E, et al. (2010) Bisphosphonate-related osteonecrosis of the jaw: is $\mathrm{pH}$ the missing part in the pathogenesis puzzle? J Oral Maxillofac Surg 68: 1158-1161. [Crossref]

27. Subramanian G, Cohen HV, Quek SY (2011) A model for the pathogenesis of bisphosphonate-associated osteonecrosis of the jaw and teriparatide's potential role in its resolution. Oral Surg Oral Med Oral Pathol Oral Radiol Endod 112: 744-753. [Crossref]

28. Ziebart T, Pabst A, Klein MO, Kämmerer P, Gauss L, et al. (2011) Bisphosphonates: restrictions for vasculogenesis and angiogenesis: inhibition of cell function of endothelial progenitor cells and mature endothelial cells in vitro. Clin Oral Investig 15: 105-111. [Crossref]

29. Wehrhan F, Stockmann P, Nkenke E, Schlegel KA, Guentsch A, et al. (2011) Differential impairment of vascularization and angiogenesis in bisphosphonateassociated osteonecrosis of the jaw-related mucoperiosteal tissue. Oral Surg Oral Med Oral Pathol Oral Radiol Endod 112: 216-221. [Crossref]

30. Lee CY, Pien FD, Suzuki JB (2011) Identification and treatment of bisphosphonateassociated actinomycotic osteonecrosis of the jaws. Implant Dent 20: 331-336. [Crossref]

31. Ruggiero SL, Dodson TB, Assael LA, Landesberg R, Marx RE, et al. (2009) American Association of Oral and Maxillofacial Surgeons position paper on bisphosphonaterelated osteonecrosis of the jaws--2009 update. J Oral Maxillofac Surg 67: 2-12. [Crossref]

32. Ruggiero SL, Dodson TB, Fantasia J, Goodday R, Aghaloo T, et al. (2014) American Association of Oral and Maxillofacial Surgeons position paper on medication-related osteonecrosis of the jaw--2014 update. J Oral Maxillofac Surg 72: 1938-1956. [Crossref]
33. Bamias A, Kastritis E, Bamia C, Moulopoulos LA, Melakopoulos I, et al. (2005) Osteonecrosis of the jaw in cancer after treatment with bisphosphonates: incidence and risk factors. J Clin Oncol 23: 8580-8587. [Crossref]

34. Wang EP, Kaban LB, Strewler GJ, Raje N, Troulis MJ (2007) Incidence of osteonecrosis of the jaw in patients with multiple myeloma and breast or prostate cancer on intravenous bisphosphonate therapy. J Oral Maxillofac Surg 65: 1328-1331. [Crossref]

35. Altman DG, Bland JM (1998) Time to event (survival) data. BMJ 317: 468-469. [Crossref]

36. Clark TG, Bradburn MJ, Love SB, Altman DG (2003) Survival analysis part I: basic concepts and first analyses. Br J Cancer 89: 232-238. [Crossref]

37. Mavrokokki T, Cheng A, Stein B, Goss A (2007) Nature and frequency of bisphosphonate-associated osteonecrosis of the jaws in Australia. J Oral Maxillofac Surg 65: 415-423. [Crossref]

38. Palaska PK, Cartsos V, Zavras AI (2009) Bisphosphonates and time to osteonecrosis development. Oncologist 14: 1154-1166. [Crossref]

39. Statement by Merck \& Co. (2012) Regarding Fosamax (alendronate sodium) and rare cases of oseteonecrosis of the jaw. Product News.

40. Grana J, Mahia IV, Meisozo MO, et al. (2008) Multiple osteonecrosis of the jaw, oral bisphosphonate therapy and refractory rheumatoid arthritis (pathological fracture associated with ONJ and BP use for osteoporosis). Clin Exp Rheumatol 26:384-385.

41. Nase JB, Suzuki JB (2006) Osteonecrosis of the jaw and oral bisphosphonate treatment. J Am Dent Assoc 137: 1115-1119. [Crossref]

42. Lazarovici TS, Yahalom R, Taicher S, Elad S, Hardan I, et al. (2009) Bisphosphonaterelated osteonecrosis of the jaws: a single-center study of 101 patients. $J$ Oral Maxillofac Surg 67: 850-855. [Crossref]

43. Lo JC, O'Ryan FS, Gordon NP, Yang J, Hui RL, et al. (2010) Prevalence of osteonecrosis of the jaw in patients with oral bisphosphonate exposure. J Oral Maxillofac Surg 68 : 243-253. [Crossref]

44. Starck WJ, Epker BN (1995) Failure of osseointegrated dental implants after diphosphonate therapy for osteoporosis: a case report. Int J Oral Maxillofac Implants 10: 74-78. [Crossref]

45. Scully C, Madrid C, Bagan J (2006) Dental endosseous implants in patients on bisphosphonate therapy. Implant Dent 15: 212-218. [Crossref]

46. Wang HL, Weber D, McCauley LK (2007) Effect of long-term oral bisphosphonates on implant wound healing: literature review and a case report. J Periodontol 78: 584 594. [Crossref]

47. Yuan K, Chen KC, Chan YJ, Tsai CC, Chen HH, et al. (2012) Dental implant failure associated with bacterial infection and long-term bisphosphonate usage: a case report. Implant Dent 21: 3-7. [Crossref]

48. Jeffcoat MK (2006) Safety of oral bisphosphonates: controlled studies on alveolar bone. Int J Oral Maxillofac Implants 21: 349-353. [Crossref]

49. Fugazzotto PA (2007) Implant placement with or without simultaneous tooth extraction in patients taking oral bisphosphonates: Postoperative healing, early follow-up, and the incidence of complications in two private practices. J Periodontol 78:1664-1669. [Crossref]

50. Grant BT, Amenedo C, Freeman K, Kraut RA (2008) Outcomes of placing dental implants in patients taking oral bisphosphonates: a review of 115 cases. J Oral Maxillofac Surg 66: 223-230. [Crossref]

51. Bell BM, Bell RE (2008) Oral bisphosphonates and dental implants: a retrospective study. J Oral Maxillofac Surg 66: 1022-1024. [Crossref]

Copyright: $(02015$ Lee CYS. This is an open-access article distributed under the terms of the Creative Commons Attribution License, which permits unrestricted use, distribution, and reproduction in any medium, provided the original author and source are credited. 